\title{
Management and Care - The Changing Landscape of Multiple Sclerosis
}

\author{
a report by \\ Cindy Lee ${ }^{1}$ and Pat Wong ${ }^{2}$ \\ 1. Editor; 2. Senior Editor, Touch Briefings
}

DOI:10.17925/ENR.2008.03.02.77

\section{Management and Care - The Changing Landscape of Multiple Sclerosis}

In early June 2008, the 18th meeting of the European Neurological Society (ENS) welcomed over 3,000 neurologists and physicians from all over the world to Nice, France. Among the multitude of symposia, oral sessions and scientific programmes on the latest in the progress made in neurodegenerative diseases were presentations by leaders in the field of multiple sclerosis (MS). Noted key points discussed included new developments in research, and the concept that drug efficacy varies depending on the treatment stage: beginning treatment earlier in the course of the disease may be more beneficial. With strong evidence presented in support of initiating treatment earlier, neurologists have been offered the opportunity to protect patients against disease progression. By implementing early intervention it may be possible to improve the prognosis of this debilitating neurodegenerative disease.

\section{Latest Developments in Multiple Sclerosis}

In a symposium discussing autoimmune disorders of the nervous system, Professor Giancarlo Comi (Italy) addressed important new issues arising from recent MS research on disease prevalence, causal factors, disease evolution and MS therapy. Recent epidemiological studies have suggested an increase in the prevalence of MS in a number of European nations - Spain, ${ }^{1}$ France, ${ }^{2}$ Greece, ${ }^{3}$ Germany ${ }^{4}$ and Italy 5,6 - particularly in the last five years. There is a trend for a nearly exclusive increase of the disease in women compared with men, says Professor Comi, attributed to lifestyle changes in women or improvements in hygiene and control of early childhood infections.

The role of genetics and environment as causal factors of MS continues to be debated. The genome-wide approach has identified interleukin-7 receptor alpha (IL-7 r $\alpha$ ) and interleukin-2 receptor alpha (IL-2 r $\alpha$ ) alleles as risk factors for developing MS. ${ }^{8}$ There is also evidence of an association between developing MS and low exposure to sunlight and vitamin $D, 9,10$ and much research is being conducted on the relationship between MS and Epstein-Barr virus (EBV) and, more recently, varicella zoster virus (VZV). EBV RNA ${ }^{11}$ and EBV antigens ${ }^{12}$ have been detected in a high proportion of brain tissue samples from MS patients, indicative of a role for EBV in MS immunopathology. There is also evidence of a very strong correlation between the viral load of VZV in cerebrospinal fluid (CSF) and blood samples and the appearance of an MS attack.13

Other research has focused on the mechanisms concerning the irreversible damage to the central nervous system (CNS) during disease progression. Not only can axonal damage and inflammation in early phases of the disease produce acute lesions, ${ }^{14}$ but it appears that initial damage can also increase damage in positive feedback loops through the overexpression of glutamate receptors, ${ }^{15}$ voltage-gated sodium channel (Nav) $1.6^{16}$ and calcium channels. ${ }^{17}$ The extent of focal atrophy around a lesion has been associated with brain atrophy and loss of volume. ${ }^{18}$ Other factors such as the duration of the inflammation, the size of the lesion and the location of the lesion have been linked to predicting the degree of persistent damage. ${ }^{19}$ Furthermore, lesion damage has been found to evolve continuously in all phases of the disease in as little as a 12-month follow-up. ${ }^{20}$ With such detrimental effects on the brains of MS patients, Professor Comi concluded this presentation with a call to improve treatment by increasing accessibility to new treatments and improving the ability to better apply existing therapies.

\section{Optimising Therapy Through Earlier Treatment and Drug Selection in Different Phases of the Disease}

A theme common to many of the MS presentations at the ENS was to initiate MS therapy at an earlier stage, not just when a clinically definitive diagnosis has been made. Many clinical trials have shown a dissociation between disease progression and inflammation, supporting the hypothesis that MS is primarily an inflammatory disorder and that inflammatory axonal injury underlies the formation of new lesions and axonal degeneration. ${ }^{21}$ By protecting against inflammation, it may then be possible to slow progression in MS, and in turn reduce the degree of tissue injury and degeneration of the nervous system. According to Professor Alistair Compston (UK) in his talk about the rationale for early treatment, offering immunological therapies early in the course of the disease - before the cascade of events leading to axonal degeneration is irreversibly established - may be most beneficial in preventing sustained disability and disease progression. Indeed, early treatment has been shown to limit axonal damage and protect against irreversible nervous damage and ensuing disability. ${ }^{22}$

\section{Treatment After a Clinically Isolated Syndrome}

Patients who have experienced a clinically isolated syndrome (CIS) are at high risk of developing clinically definite MS (CDMS). Epidemiological studies and clinical trials have shown that approximately $85 \%$ of CIS patients are diagnosed with MS within two years. ${ }^{23}$ It is at this early stage of the disease that treatment should be initiated, elaborated Professor Comi, with evidence from magnetic resonance imaging (MRI) studies showing brain atrophy and decreased brain volume in the very early stages of MS. ${ }^{24,25}$

All three clinical trials testing the use of interferon beta formulations in CIS patients - the Betaferon/Betaseron in Newly Emerging Multiple Sclerosis For Initial Treatment (BENEFIT) study, the Controlled High-risk Avonex Multiple Sclerosis Prevention study (CHAMPS) study and the Early Treatment Of MS (ETOMS) study - have shown obvious advantages with early therapy, including a reduced rate of conversion 


\section{Improving Patient Outcome Through Earlier Treatment}

In her presentation entitled 'Earlier is better - the importance of MS treatment', Dr Mar Tintoré (Spain) explained that a first neurological event warrants early treatment because of the events that occur early in the disease course. Early axonal damage is correlated to inflammation and may be irreversible, and atrophy appears soon after the occurrence of a clinically isolated syndrome (CIS). ${ }^{14,25}$ Early factors have a significant impact in the long term; evidence from natural history studies negatively correlates the number of attacks in the early years of the disease with the time it takes to reach greater disability and disease severity, ${ }^{73}$ and the time interval between the first and second attacks has proved to be a major clinical factor in predicting long-term disability. ${ }^{74}$ Magnetic resonance imaging (MRI) parameters have also proved useful in assessing the risk of multiple sclerosis (MS) disease progression; CIS patients followed for a median of seven years showed that those who developed new T2 lesions faced an increased risk of progressing to clinically definite MS (CDMS). Furthermore, increases in lesion volume are correlated with greater long-term disability. ${ }^{75}$ Indeed, the CHAMPS and PreCISe studies in monofocal patients and the ETOMS and BENEFIT studies in mono- and multifocal patients have all shown that early treatment can significantly delay the development to CDMS compared with placebo (see Figure 1).

Another important message raised in recent years is that drug efficacy may vary depending on the disease phase. In the CIS stage, drug efficacy is around 50\%, but drops to $30 \%$ for patients in the relapsing-remitting phase and continues to decrease through the disease course (see Figure 2). This key concept has been seen with a number of different drugs, says Dr Tintoré, with the same drug having greater efficacy when introduced earlier. If physicians delay in treating patients, then not only are patients at greater risk of earlier disease progression and disability, but when they finally receive disease-modifying therapies they will experience much less efficacy.

A similar emphasis on early treatment was expressed by Professor David Bates (UK). Initial inflammation of the nervous system occurs early in the disease, leading to demyelination and subsequent axonal loss. This inflammation may occur in a pre-clinical way, where it is unnoticed until a patient experiences a clearly eloquent attack. Throughout the disease, a majority of patients will experience a gradual loss of brain tissue and continued and increasing damage to the axons, with progressive deterioration in cognition and memory, all the while showing a gradual increase in damage on the MRI scan (see Figure 3). Because the available MS treatments are predominantly anti-inflammatory, it follows that their greatest effect will take place at the beginning of the disease course when the nervous system is inflamed. Although the available

\section{Figure 1: Studies in Clinically Isolated Syndrome Population}

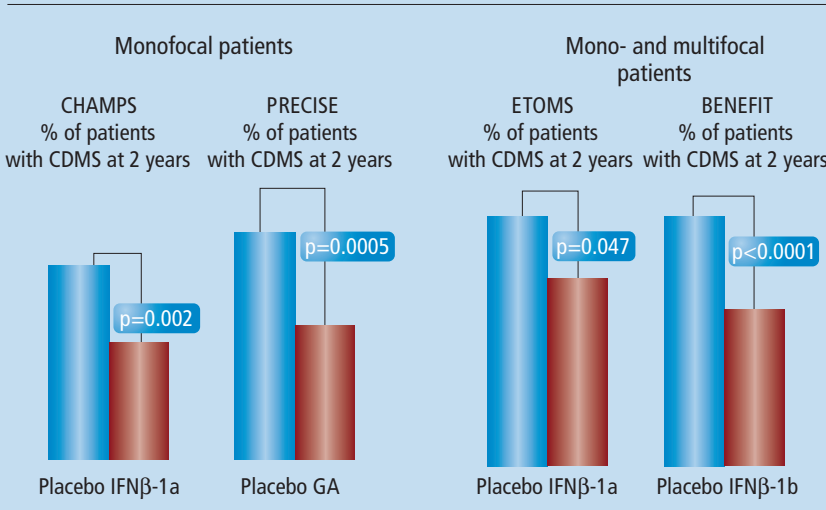

Source: Comi et al., 2001,26 Jacobs et al., 200027 and Kappos et al., 2006.28

Figure 2: Treatment Effect in Relapsing Forms of Multiple Sclersosis

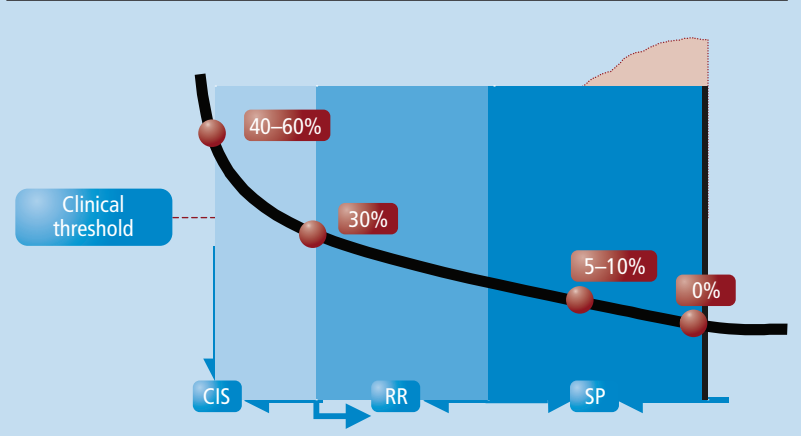

A simplified diagram depicting the effect of disease-modifying agents throughout the disease course. Drug efficacy is around 50\% for patients with clinically isolated syndrome (CIS), but this efficacy is reduced to $30 \%$ by the time these patients advance to the relapsing-remitting (RR) phase. Further progression to the secondary progressive (SP) state of the disease results in even greater declines in drug efficacy.

Figure 3: Natural Progression of Multiple Sclerosis

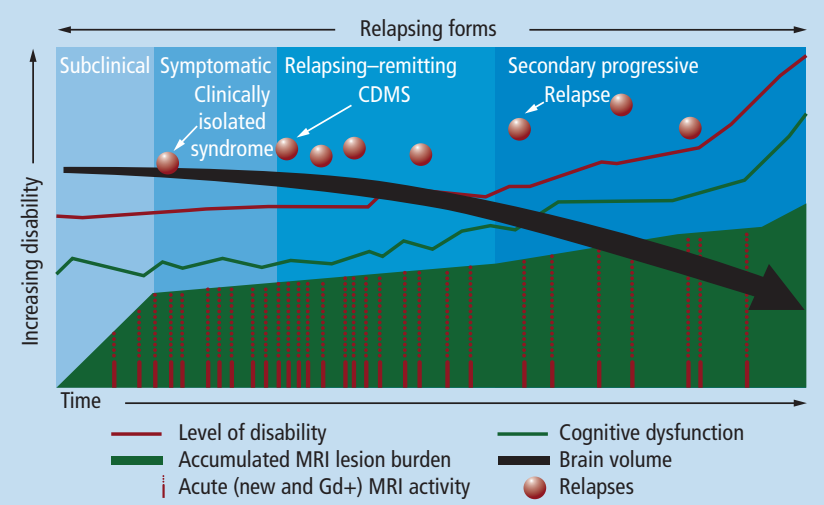

MS therapies do show an effect in the later courses of the disease, their ability to prevent subsequent deterioration is unlikely. to CDMS (see Table 1), prolonged time to a second attack and reduced brain MRI activity. ${ }^{26-28}$ Furthermore, extensions of these studies with at least three years of follow-up confirm that CIS patients who received early therapy continued to benefit significantly in terms of preventing a second attack. ${ }^{29,30}$ The BENEFIT trial revealed that even as little as three years of early treatment can significantly reduce the risk (by $40 \%$ ) of confirmed expanded disability status scale (EDSS) progression compared with patients in whom treatment with interferon beta- $1 \mathrm{~b}$ (Betaferon, Bayer Schering Pharma) was delayed,.29 Furthermore, the prospectively planned follow-up study showed that after three years this early treatment conferred an advantage in cognitive function over patients who received delayed treatment $(p=0.011)$, as scored by the Paced Auditory Serial Addition Test (PASAT), which measures intellectual function and cognition. A retrospective follow-up of 
CHAMPS (the Controlled High Risk Avonex Multiple Sclerosis Prevention Study in Ongoing Neurologic Surveillance [CHAMPIONS Study]) after five years found that early treatment with interferon beta-1a could significantly lower the cumulative probability of developing CDMS compared with delayed treatment. ${ }^{30}$ The results of the Study to Evaluate the Efficacy of Early Glatiramer Acetate in Delaying the Conversion to CDMS of Subjects Presenting With a Clinically Isolated Syndrome (PreCISe), presented in a separate session by Professors Comi and Massimo Filippi on behalf of the PreCISe study group, showed that compared with placebo, glatiramer acetate (Copaxone, Teva Pharmaceutical) reduced the risk of developing CDMS by $45 \% .{ }^{31}$ Interferon beta-1a has also shown clinical and cognitive benefits for patients with early relapsing-remitting MS (RRMS) in the Cognition Impairment in Multiple Sclerosis (COGIMUS) study at two and three years, respectively. ${ }^{32}$ Furthermore, evidence from a Cochrane meta-analysis supports the idea of early treatment; interferon beta therapy applied early - at the time of the first episode suggestive of MS - showed significant ability in preventing the conversion from CIS to CDMS in all studies analysed, with benefits persisting through two years of treatment. ${ }^{33}$

So, should all patients with a CIS be treated immediately following the first neurological episode? Not necessarily, says Professor Comi, as it depends largely on the patient's clinical presentation. Rather, the following prognostic factors - as determined from ETOMS, CHAMPS, BENEFIT and PreCISe - can help to predict which CIS patients are at increased risk of early conversion to CDMS:

- $\geq 9$ T2 lesions;

- $>1$ gadolinium-enhancing ( $\mathrm{Gd}+$ ) lesion;

- multifocal presentation;

- higher clinically and MRI-measured disease severity at onset, with a longer pre-clinical phase and/or more aggressive disease course; and

- ongoing brain activity in the MRI indicative of inflammation.

According to Professor Comi's personal recommendations for patients with a first attack and brain MRI suggestive of MS, early treatment should be initiated for those exhibiting one or more negative prognostic factor, whereas those lacking negative prognostic factors should be carefully monitored and given repeat MRIs, with therapy being initiated on evidence of temporal dissemination. Patients who have suffered an attack but retain otherwise normal brain MRI or an MRI scan atypical of MS are at low risk of conversion to CDMS or disability, and should undergo annual MRI scans. ${ }^{34}$ However, Professor Comi does stress that he disagrees with the generalisation that CIS patients should not be treated with immunomodulatory drugs because of the chance that a subgroup may have a benign disease course. The reason for this is that the purpose of treating CIS patients is to anticipate and prevent potential damage; this is significant as $85-94 \%$ of untreated CIS patients have new attacks or lesion formations within two years of the original clinical event. $23,26,27$ Unfortunately, there are still some European countries that do not reimburse treatment for CIS patients, and many of these affected patients are denied access to highly effective therapies.

Treatment of Clinically Definite Multiple Sclerosis

The past 15 years have seen an expansion in the therapeutic armamentarium against MS from just interferon beta-1b alone to a small group of immunosuppressants and immunomodulatory drugs, and
Table 1: Risk Reduction for Progression to Clinically Definite Multiple Sclerosis

\begin{tabular}{llll} 
Studies in Multi- and Monofocal Patients & $\mathrm{n}$ & Risk Reduction (\%) & $\mathrm{p}$-value \\
\hline BENEFIT & 468 & 50 & $<0.0001$ \\
\hline ETOMS & 309 & 35 & 0.045 \\
\hline Monofocal patients only & $\mathrm{n}$ & Risk Reduction (\%) & $\mathrm{p}$-value \\
\hline BENEFIT & 246 & 55 & $<0.0001$ \\
\hline CHAMPS & 383 & 44 & 0.002 \\
\hline PRECISE & 481 & 45 & 0.0005 \\
\hline
\end{tabular}

Source: Comi et al., 2001, ${ }^{26}$ Jacobs et al., 2000, ${ }^{27}$ Beck et al., 2002, ${ }^{23}$ Kappos et al., 2006, ${ }^{28}$ Kappos et al., $2007^{29}$ and Comi and Filipi, 2008. ${ }^{100}$

although this continually growing collection provides treatment options for patients with MS, it has also greatly complicated the selection of any specific drug for treatment at a given disease stage. However, stresses Professor Christian Confavreux (France), initiating treatment as soon as possible is essential - and the earlier, the better.

Although it may prove useful to follow official guidelines such as those provided by the European Federation of Neurological Societies, 35 the patient's disease phase must also be assessed as the initial step in selecting a treatment, accounting primarily for the clinical activity, with MRI activity as secondary criterion. It is known that the currently available treatments of interferon beta and glatiramer acetate can improve patient outcome by reducing the rates of relapse frequency and MRI activity. However, longterm efficacy in delaying disability remains uncertain. Drawing on the data from the head-to-head comparisons Betaferon Efficacy Yielding Outcomes of a New Dose (BEYOND), ${ }^{36}$ Rebif vs Glatiramer Acetate in Relapsing MS Disease (REGARD) 37 and Betaseron vs Copaxone in MS with Triple-Dose Gadolinium and 3-T MRI Endpoints (BECOME), 38 Professor Confavreux concluded that the similarities in efficacy and long-term safety exhibited by the interferon betas and glatiramer acetate qualifies them as prime candidates in the first-line treatment of active forms of RRMS.

The efficacy of natalizumab is even greater, with a $68 \%$ reduction in relapse rate and $83 \%$ reduction of new or enlarging $\mathrm{T} 2$ lesions, ${ }^{39}$ but it is indicated as a second-line therapy for RRMS patients who have failed treatment with interferon beta or glatiramer acetate, or for treatmentnaïve patients with rapidly evolving severe MS.40 However, the association with serious and fatal infection such as progressive multifocal leukoencephalopathy (PML) and possible neoplastic complications requires close monitoring upon prescribing natalizumab. Immunosuppressive third-line therapies such as mitoxantrone or cyclophosphamide are recommended for severe aggressive MS or disease breakthrough.

Deciding on a treatment is rarely as simple and clear-cut as following recommendations, however; MS is a long-term, chronic and very heterogeneous disease, with disease activation presenting differently between patients. Patient characteristics, such as age at onset and apparent disease severity, and clinical factors, such as drug efficacy, safety and tolerability, need to be considered together in assessing treatment options; ultimately, any chosen therapy should have an extremely important effect on the disease pattern and future prognosis of MS.

\section{Induction Therapy in Multiple Sclerosis}

There are cases where patients continue to experience frequent relapses and disease progression despite disease-modifying therapy. Combination therapy is typically designated for treatment failures, and 


\section{Benign versus Non-benign MS - Is Disability Only a Factor of Time?}

As a proponent of early treatment, Dr Mar Tintoré spoke of the problems in diagnosing patients as having benign multiple sclerosis (MS). In a longitudinal study, $48 \%$ of patients initially classified as benign by their neurologists 10 years after disease onset were found to be non-benign after a further 10 years of follow-up, progressing from expanded disability status scale (EDSS) $<3.0$ to EDSS $\geq 3.5 .^{76,77}$ Furthermore, nearly half of patients considered benign have exhibited cognitive impairment. ${ }^{78}$ Benign MS may therefore become non-benign MS over time.

Illustrating an even more dramatic impact, Professor Bernd Kieseier (Germany) addressed a study where out of 47 benign patients followed up for 21 years, 18 had died, 22 had become disabled and only seven had remained benign. ${ }^{79}$ The authors of this study concluded that classifying patients as benign after 10 years of EDSS $\leq 3.0$ has poor predictive value. Professor Kieseier adamantly expressed that there is no way to predict whether a patient has benign MS, and that in his opinion there may not even truly be a benign condition: if the brains of MS patients and those of unafflicted individuals were compared, inflammation and cell damage would still be found regardless. Given that MS is a chronic disease with ongoing inflammation, there is an urgency to treat these patients as early as possible.

the few studies available are limited in sample size, efficacy data or longterm safety data; a large-scale randomised, double-blind, placebocontrolled study sponsored by the National Institutes of Health $(\mathrm{NIH})$ is currently enrolling to determine the effects of glatiramer acetate/interferon beta-1a (Avonex, Biogen Idec) combination therapy. Alternatively, induction therapy using immunosuppressants followed by immunomodulatory agents has been proposed to offer benefits to clinically active relapsing MS patients. Presenting on this topic, Dr Robert Lisak (US) debated the rationale behind induction therapy and for which patients it would be appropriate.

Small studies have shown that patients who received induction therapy had significantly lower MRI activity compared with those who did not, ${ }^{41,42}$ with the potential to reduce EDSS progression by $65 \%$, sustained by a decrease of $61.5 \%$ in the annualised relapse rate and no significant adverse effects..$^{43}$ Intense immunosuppression is often used as rescue or disease-stabilising therapy for actively relapsing MS patients with suboptimal response to immunomodulatory agents, but very little data are available regarding the use of intense immunosuppression as initial MS therapy. Patients who received monthly cyclophosphamide intravenously for six months before initiating disease-modifying therapy with interferons or glatiramer acetate showed significant reductions in mean EDSS, relapse rate and $\mathrm{Gd}+$ lesions one year after immunosuppression was initiated, with good tolerance and no adverse events. ${ }^{44}$ Data from a one-year follow-up are expected. However, there is a caveat, warns Dr Lisak, because even short-term use of immunosuppressants may pose long-term risks, including oncogenesis, ${ }^{45}$ infertility and congestive heart failure, depending on the choice of antisuppressant.
Similar to the problem of identifying which patients qualify for early MS treatment, those with suboptimal responses also need to be identified for treatment, be it by switching between immunomodulatory agents or switching from immunomodulation to immunosuppression; so far, clinical criteria, MRI criteria and biomarkers have been the most help in selecting patients for induction therapy. ${ }^{46} \mathrm{Dr}$ Lisak concluded that a composite using criteria indicative of highly active disease that clearly warrants induction with immunosuppressive therapy is necessary, and presented provisional recommendations put together by himself and his colleague Dr Omar Khan (US). These recommendations state that observing any three or more of the following criteria in a patient should compel the clinician to initiate immunosuppressive therapy:

- >2 relapses in the past 12 months requiring corticosteroid treatment;

- recurrent brain stem or spinal cord relapses;

- EDSS >3.0 within three to six months following the last relapse;

- $\geq 3 \mathrm{Gd}+$ lesions that are $>3 \mathrm{~mm}$ in size on a single scan;

- $\geq 3$ new T2 lesions in the past 12 months; and

- any evidence of atrophy.

\section{Diagnosing Benign Multiple Sclerosis}

Designating a case of MS as benign confers a favourable course of MS in which such patients experience mild or no disability after the initial clinical onset. However, an increasing amount of emerging data has instigated great debate as to how benign MS can be diagnosed with absolute certainty, and whether or not such a condition actually exists. The problem with this label is that patients with benign MS are under the impression that their symptoms will not worsen, and as a result will be unlikely to seek out the same level of medical attention as patients who have been diagnosed with CDMS. Moreover, for benign patients who become nonbenign over time, this poses a great loss in terms of health and protection against disability that could otherwise have been prolonged or delayed with early treatment.

Patients with benign MS experience fewer lesions than patients with early RRMS. ${ }^{47}$ However, lesion load has been found to be higher in benign patients than in those with early RRMS ${ }^{48}$ and those with non-disabling RRMS. ${ }^{49}$ Furthermore, no significant difference could be found in normal brain volume and, by association, neuroaxonal brain viability between benign and early RRMS patients. ${ }^{49}$ The researchers of these studies argue that patients with benign MS experience a relative sparing of cortical damage, which then bestows upon them favourable clinical disease courses, but the presence of lesions in benign patients and the fact that these patients have an increase in lesion loads cannot be ignored. Cognitive dysfunction in benign MS is also associated with significantly more severe damage to the corpus callosum, with significantly higher lesion load compared with benign patients without cognitive impairment. ${ }^{50}$

\section{Updates on Efficacy in Recommended \\ Multiple Sclerosis Therapies}

Prior to prescribing any sort of treatment to a patient, drug efficacy, safety and tolerability are all factors that must be carefully considered. This section of the report will focus on the advances and recent research that have been made available in these areas, as discussed at the ENS, as well as a special focus on the up-and-coming drugs in development.

Conclusive comparisons between the various therapies available for MS have been rather difficult because to date there has been no single study 


\section{From Clinical Trials to Clinical Practice}

With three years of the planned five-year follow-up to the BENEFIT study completed, data show that there are indeed advantages for early treatment with interferon beta-1b (Betaferon) following the initial demyelinating event. Presenting on the efficacy of Betaferon in early disease stages, Professor Comi indicated a greater reduction in relapse rate and risk of progression to clinically definite multiple sclerosis (CDMS) over three years with early treatment compared with delayed treatment and, as previously mentioned, a delay in the time to confirmed expanded disability status scale (EDSS) progression. ${ }^{29}$ After three years of follow-up, only $37 \%$ of patients receiving early treatment developed CDMS, a risk reduction of $41 \%$, compared with the $51 \%$ of patients who received delayed treatment. The risk of progression to disability was also reduced by $40 \%$, with $16 \%$ of early-treated patients diagnosed with confirmed EDSS progression compared with $24 \%$ of patients with delayed treatment. This study holds an important message: the early intervention is not just a delay in worsening conditions or a modification of the debilitating disease, but, according to Professor Comi, a demonstration that these patients are being treated for the accumulation of irreversible damage. Furthermore, the already highly significant results from BENEFIT are likely understated since a majority of the delayed-treatment arm received at least one year of interferon beta- $1 b$ as well. The five-year follow-up study is set to be completed in 2008, and the BENEFIT project has been extended to analyse various outcomes, including time to CDMS and MS according to the McDonald criteria, disability, quality of life, magnetic resonance imaging (MRI) measures and adherence.

As part of the symposium 'Targeting the pathophysiology of MS: transforming discovery into care', Dr Kieseier spoke about the importance of initiating treatment at diagnosis, in which a 'window of opportunity' exists to offer neurologists the chance to possibly maintain an isolated syndrome and avoid future progression to secondary progression or chronic illness (see Figure 4). All patients in the CHAMPS study received interferon beta-1a intramuscularly, but those randomised to receive immediate treatment from study onset rather than placebo and delayed interferon beta-1a experienced greater benefits with reduced risk of progression to CDMS and annualised relapse rate over five years. ${ }^{27,30}$ Additionally, interferon beta-1a has been shown to decrease the mean number of MRI lesions, brain atrophy ${ }^{80}$ and cognitive dysfunction. ${ }^{81}$ Dr Kieseier noted that patients who receive delayed treatment never quite catch up with those receiving early treatment in terms of experiencing the same benefits.
Figure 4: Early Treatment May Slow the Natural Course of Multiple Sclerosis

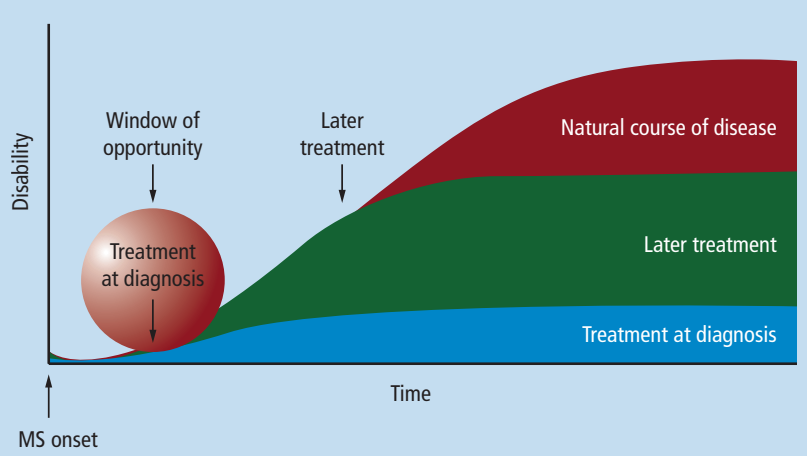

The next speaker in this symposium, Dr Norman Putzki (Germany), presented an argument supporting the role of natalizumab as an anti-inflammatory drug in MS. With the drug indicated for patients with more active disease, a sub-analysis of highly active patients who were placebo-treated in the AFFIRM trial showed that natalizumab retained similar efficacy in active disease to that seen in patients who received natalizumab earlier, and in so doing was able to reduce the annualised relapse rate of these highly active patients. Risk reduction of disease progression over two years decreased by more than $50 \%$, and this effect was observed in highly active patients as well. ${ }^{39}$ Crucial to demonstrating the relative difference between receiving and not receiving treatment, according to Dr Putzki, is the fact that natalizumab increased the proportion of patients free of clinical or MRI disease activity by fivefold, regardless of baseline severity. ${ }^{82}$

Cases of progressive multifocal leukoencephalopathy (PML) have previously been reported for natalizumab/interferon beta-1a combination therapy, which led to the temporary withdrawal of natalizumab from the market. One study suggested that the likelihood of PML over 18 months of treatment would be roughly one in 1,000 patients. ${ }^{83}$ However, since the conclusion of the ENS, two new and separate cases of PML in patients receiving natalizumab monotherapy over a span of approximately 14 and 17 months, respectively, has emerged. ${ }^{84}$ With more than 43,000 patients who have been exposed to natalizumab, 85 these occurrences of PML remain in the predicted frequency of one incidence in every 1,000 patients. that has directly compared them all together in terms of efficacy and safety in a head-to-head manner. However, direct comparisons have shown that interferon beta-1 $\mathrm{b}$ administered every other day has greater efficacy than a once-weekly dose of interferon beta-1a, with significant differences in the number of patients who remained relapse-free or experienced a delay to CDMS. ${ }^{51}$ High-dose interferon beta-1a given three times a week has a greater advantage over weekly dosage in terms of the percentage of patients who are relapse- and T2-lesion-free and the number of active lesions. ${ }^{52}$ Other comparisons have shown a similar efficacy between interferon beta-1 $\mathrm{b}$ and glatiramer acetate: the BECOME study showed that treatment with interferon beta-1b led to fewer permanent black holes developing from enhancing lesions than glatiramer acetate, although no significant difference was observed in terms of ability to reduce MS activity and the mean number of combined active lesions..$^{38}$ Similarly, the REGARD study found no significant difference between the treatments in the number and change in volume of active lesions or the time to the first relapse..$^{37}$

Data from the BEYOND study presented at the ENS comparing the efficacy, safety and tolerability of interferon beta- $1 \mathrm{~b} 250 \mathrm{mcg}$, interferon beta- $1 \mathrm{~b} 500 \mathrm{mcg}$ and glatiramer acetate $20 \mathrm{mg}$ daily in RRMS patients over a period of 24 months showed no significant differences between any of the treatment arms in relapse risk, the number or volume of $\mathrm{T} 1$ 


\section{Improving Tolerability as a Means of Ameliorating Drug Therapy}

Presenting data from the Rebif New Formulation Study, Dr William Camus (France) spoke of the improvements in immunogenicity, safety and tolerability. The objective of the phase IIIb single-arm, open-label Rebif New Formulation (RNF) Study was to evaluate the product's safety and immunogenicity in relapsing-remitting multiple sclerosis (RRMS). Enrolment criteria required patients aged 18-60 years of age with expanded disability status scale (EDSS) $<6.0$ to be naïve to treatment with interferon beta. Patients selfinjected RNF at $44 \mathrm{mcg}$ three times a week over a period of two years. Patients treated with RNF had a lower rate of neutralising antibodies compared with data from the EVIDENCE and REGARD studies, indicative of an improved immunogenical profile, and also experienced a significant reduction in annualised relapse rate..$^{59}$

Focusing on adverse events, there was a nearly three-fold reduction in injection-site reactions compared with previous studies, at $30.8 \%$ compared with 85.8 and $41.2 \%$ in the EVIDENCE and REGARD studies, respectively. Surprisingly, though, flu-like symptoms were much higher, at $71.5 \%$ versus 49.0 and $36.0 \%$ in the EVIDENCE and REGARD studies, respectively, 60 which has prompted researchers to further analyse this issue through the Transition to Rebif New Formulation (TRANSFER) study.

$\mathrm{Gd}+$ lesions or $\mathrm{T} 1$ black holes or brain volume. ${ }^{53}$ A similarly high proportion of patients in each arm were free from disease activity. ${ }^{54}$ However, T2 lesion volume change and cumulative volume were lower in groups using interferon beta-1b compared with glatiramer acetate, suggesting that there may be different effects on the overall disease burden depending on treatment. 53

Natalizumab has been recommended as second-line therapy for patients who continue to progress while receiving the first-line disease-modifying therapies. Patients with relapsing MS in the Natalizumab Safety and Efficacy in Relapsing Remitting Multiple Sclerosis (AFFIRM) or Safety and Efficacy of Natalizumab in Combination with Interferon Beta-1a in Patients with Relapsing Remitting Multiple Sclerosis (SENTINEL) trials were monitored for disease activity, and researchers found that natalizumab, whether as a monotherapy or in combination with interferon beta- $1 \mathrm{a}$, yielded a significantly higher proportion of disease-activity-free patients compared with placebo over two years based on both clinical and MRI data measures. ${ }^{55}$ Although approved for use as in RRMS, natalizumab is associated with fatigue and allergic reactions, as well as potentially fatal adverse events such as anaphylactic shock, progressive multifocal leukoencephalopathy, infections and clinically significant liver damage. These safety issues and the lack of information regarding long-term use has led to reservations over using the drug outside of clinical research.

Although mitoxantrone has been suggested for aggressive forms of MS, it has also been associated with a risk of oncogenesis. The prevalence of acute myeloid leukaemia (AML) is significantly increased in MS patients who receive mitoxantrone treatment, and appears to occur in younger patients. No apparent correlation was found between previous MS treatments and cumulative mitoxantrone dose with the risk of developing AML.. ${ }^{45}$
The Effect of Tolerability on Adherence and Quality of Life For a patient to maintain adherence and reap the complete benefits of their disease-modifying therapy, their treatment must be tolerable. MS patients often experience headaches, and headaches related to treatment with interferon beta that were independent of flu-like symptoms have recently been found to be more frequent than previously reported. Although not a contraindication to therapy with interferon beta, physicians are suggested to monitor patients for headaches and to adjust therapy if the frequency increases. ${ }^{56}$

The BENEFIT studies have demonstrated good tolerability to interferon beta- $1 \mathrm{~b}$ in patients with CIS, with a high adherence rate after three years $(>73.3 \%)$ and a large proportion (>89.3\%) of patients choosing to continue therapy in the follow-up study. ${ }^{.7} \mathrm{~A}$ comparison of tolerability between interferon beta-1b $250 \mathrm{mcg}$ and glatiramer acetate in the BEYOND study showed that patients treated with interferon were more likely to experience flu-like symptoms, although the incidence of this adverse effect decreased with time. In contrast, injection-site reactions were commonly reported by patients receiving glatiramer acetate. ${ }^{58}$

The new formulation of interferon beta-1a (Rebif new formulation [RNF]), produced without foetal bovine serum and human serum albumin, has shown reduced immunogenicity compared with the current formulation in patients with relapsing MS. ${ }^{59,60}$ The incidence of serious adverse events was similar to that seen in data from the Evidence of Interferon Dose-response: European North American Comparative Efficacy (EVIDENCE) and REGARD studies, although patients were more likely to have flu-like symptoms with RNF. However, RNF had fewer patient-reported injection-site reactions and feelings of depression. The overall safety and tolerability profile of RNF relative to the current formulation of interferon beta- $1 \mathrm{a}$ is proposed to influence treatment adherence. ${ }^{60}$

As with any chronic life-long disease, adherence to drug therapy is a major determinant of the success of the disease-modifying therapy, and this concept is no different in MS. Adherence and relapse rate are closely associated: one study has shown that patients who refused to adhere to treatment for over 90 days face a significantly increased risk of severe MS relapse compared with patients with shorter or no gaps in drugmodifying treatment. ${ }^{6}$

Studies have also shown that adherence varies depending on the drug in question. Adherence in the BEYOND trial was high in all groups, but a slightly higher number of patients treated with interferon beta- $1 \mathrm{~b}$ $250 \mathrm{mcg}(82 \%)$ saw the study through to completion compared with those treated with high-dose interferon beta-1b $500 \mathrm{mcg}(73 \%)$ or glatiramer acetate (78\%). ${ }^{36,58}$

Certainly, the results from clinical trials with respect to adherence are an area to be considered by physicians when prescribing medications for patients, and the subject of adherence is an important one, as drug compliance is closely linked to the patient's quality of life - the efficacy of a drug is irrelevant if patients exhibit poor compliance, for example, due to bad adverse effects or low tolerance, which ultimately leads to disease progression and poor patient outcome. However, quality of life is not solely dependent on drug use and compliance: one study assessed a cohort of Polish subjects with MS to determine the most important factors affecting quality of life and found depression, level of disability, fatigue and marital status to be the strongest predictors of quality of life. ${ }^{62}$ In the 


\section{Can Adherence Be Further Ameliorated?}

Presenting a comprehensive comparison of the tolerability of multiple sclerosis (MS) therapies, Dr Karl Baum (Germany) spoke about the factors affecting patient adherence. Referring to the INCOMIN and EVIDENCE trials, tolerability and adverse events were similar between the three different interferons. ${ }^{51,86}$ However, injection-site reactions occurred more frequently with Betaferon in INCOMIN (37\%) and with Rebif in EVIDENCE (81\%), both compared with Avonex (8 and $25 \%$, respectively). Furthermore, the similarities in adverse event data from the INCOMIN and EVIDENCE studies between high-dose, highfrequency therapies and glatiramer acetate or interferon beta-1a indicate that tolerability is not sacrificed for greater efficacy (see Figure 5).

The Betaferon versus Rebif Investigating Higher Tolerability (BRIGHT) study was a non-randomised prospective observational study specifically designed to compare injection-site pain and reactions in relapsing-remitting MS (RRMS) patients treated with either Betaferon or Rebif, with a subgroup analysis that explored the relationship between needle gauge and injection pain. ${ }^{87}$ Regardless of whether pain was assessed immediately or 30 or 60 minutes after the injections, a significantly higher proportion of patients treated with Betaferon experienced pain-free injections compared with patients receiving Rebif. The smaller needle gauges used by Betaferon patients were associated with less discomfort as well and, according to the speaker, could potentially lead to increased adherence.

An assessment of the BEYOND study showed a trend towards greater adherence with $250 \mathrm{mcg}$ interferon beta compared with glatiramer acetate. ${ }^{36}$ When analysing the profile of the adverse effects, injection-site reactions demonstrated a significant advantage in favour of interferon beta- $1 \mathrm{~b} 250 \mathrm{mcg}$ in comparison with glatiramer acetate, largely in the incidence of injection-site pain and injection-site pruritus. Furthermore, lipoatrophy was observed only in patients who received glatiramer acetate (see Figure 5). Systemic reactions such as dyspnoea, chest pain, flushing and chest discomfort were also significantly lower in interferontreated patients than in those who received glatiramer acetate. Reports of flu-like symptoms were more prominent in patients receiving interferon beta- $1 \mathrm{~b}$, but the incidence decreased with time in all treatment arms.

However, the issue remains of how patient adherence can be promoted. Dr Baum emphasised the fact that therapies will work only in patients who take them and, expressing a need for specialised MS nurses, presented the Betaferon Education Training and Assistance (BETA) nurse programme. This programme provides a physician's clinic with a dedicated BETA nurse, and is the only MS nurse programme with around-the-clock availability to provide free training kits, auto-injectors and sharps containers. The nurses also offer ongoing support tailored to the patient's needs, as well as access to educational events and materials, and provide personalised one-on-one injection training, in an in-home situation if the patient so wishes. In doing so, the trained nurses can identify any MS symptoms and manage any adverse events of treatment,
Figure 5: Injection-site Reactions Occurring in at Least $5 \%$ of One Group

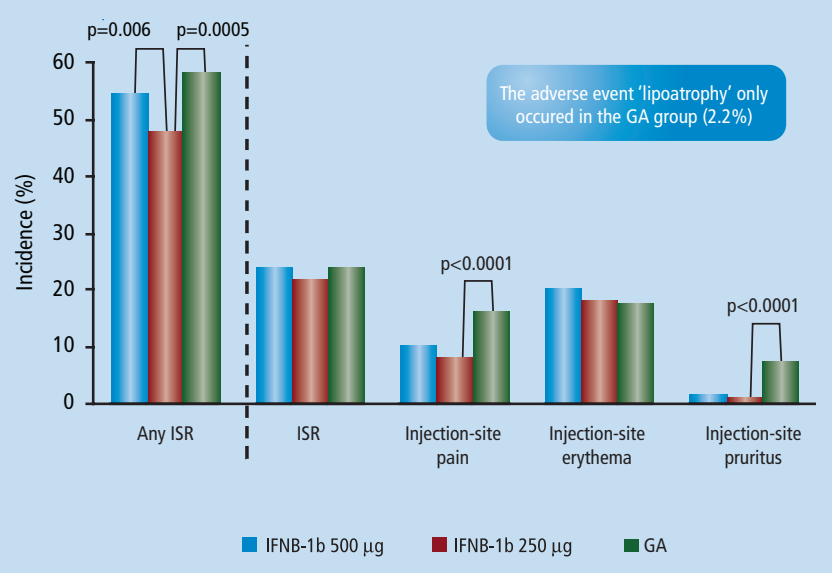

GA = glatiramer acetate; $I S R$ = injection-site reaction.

Figure 6: Benefits of the BETA Nurse Programme Patient Adherence Rates

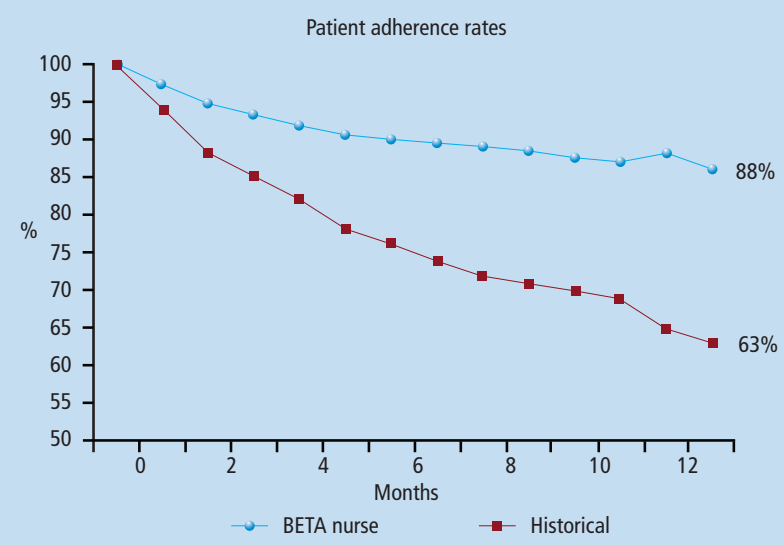

A large-scale analysis evaluated adherence to Betaferon ${ }^{\circledR}$ therapy in patients with MS enrolled in the BETA nurse programme. The analysis monitored more than 4,000 patients.

Source: Halper, 2003.88

helping to promote patient adherence and reduce decline into poor quality of life. By monitoring patients in such a way, the nurses also have the opportunity to notice any change in the patient and report back to the neurologist with updates regarding patient treatment and compliance. The MS nurse therefore plays a central role in the long-term treatment of MS patients, covering a number of potential factors relevant for increased treatment adherence.

Does it work, though? A large-scale analysis examining the adherence of over 4,000 patients enrolled in the BETA nurse programme in the US saw high rates in favour of the patients who had contact with a BETA nurse compared with the historical cohort who did not after 13 months (88 versus 63\%) (see Figure 6). 88 The new Betaferon prospective study on Adherence, Coping and Nurse support (BEACON) study is an international, multicentre, non-interventional study that centres on MS nurse activities and their influence on adherence, and aims to increase knowledge about early treatment cessation, the reasons for doing so and predictive factors. 


\section{An Emergence of Oral Therapies}

Considering that all currently available therapies for multiple sclerosis (MS) require regular parenteral administration, oral therapies are indeed a step forward in drug development. Several are in phase III clinical trials - laquinimod, fingolimod (FTY-720), teriflunomide, demethyl fumarate (DMF; BG12) and oral cladribine, to name a few - and with the exception of oral cladribine, which has a short-course intermittent dosing regimen, these drugs require a daily or several-times-daily dosing regimen (see Table 2). Most of these aforementioned molecules have origins in oncology or transplantation. In two separate satellite symposium proceedings, Drs Patrick Vermersch (France) and Robert Fox (US) presented recent evidence in support of oral cladribine and BG12, respectively, in the treatment of MS

Clinical and magnetic resonance imaging (MRI) data from a number of previous trials with parenteral cladribine have shown promise for the synthetic purine nucleoside analogue in treating MS. ${ }^{89-92}$ Parenteral cladribine increased the proportion of relapse-free relapsing-remitting MS (RRMS) patients and reduced the relapse rate, while also reducing the percentage of patients with $\mathrm{Gd}+\mathrm{T} 1$-lesions and suppressing $\mathrm{Gd}+$ T1-lesion volume. Parenteral cladribine also has a favourable safety profile, and was generally well tolerated by patients, with dose-related adverse events more frequent at higher doses of cladribine $(\geq 2.8 \mathrm{mg} / \mathrm{kg}$ ); however, such high doses are not used in MS. Cladribine tablets are unique in that they offer a convenient short-course dosing regimen: once daily for five days per course for a total of 10 or 20 days per year of treatment. ${ }^{93}$ This, compared with other oral MS therapies that require daily administration, has been proposed to improve adherence to therapy. ${ }^{94}$

The Cladribine Tablets Treating Multiple Sclerosis Orally (CLARITY) study is an ongoing study over a two-year period. Over the first year of treatment, patients with relapsing MS are randomised into one of three arms to receive: four courses of oral cladribine; two courses of oral cladribine followed by two courses of placebo; or four courses of placebo. In the second year, the placebo arm continued to receive placebo, while the active treatment groups received two courses of oral cladribine. The primary end-point is relapse rate. Secondary objectives include the clinical end-points disability progression, MRI parameters and safety assessments. ${ }^{95} \mathrm{~A}$ two-year extension study has since been designed to evaluate the safety of extended treatment of patients who complete the CLARITY study, as
Table 2: Oral Therapies in Development for Multiple Sclerosis

\begin{tabular}{|c|c|c|c|c|}
\hline Agent & $\begin{array}{l}\text { Treatment } \\
\text { Target }\end{array}$ & History & $\begin{array}{l}\text { Dosing } \\
\text { Regimen }\end{array}$ & $\begin{array}{l}\text { Development } \\
\text { Phase }\end{array}$ \\
\hline BG12 & $\begin{array}{l}\text { Prevention of } \\
\text { T-cell activation }\end{array}$ & $\begin{array}{l}\text { Derivative of } \\
\text { fumaric acid }\end{array}$ & $\begin{array}{l}\text { Several } \\
\text { times daily }\end{array}$ & III \\
\hline Cladribine & $\begin{array}{l}\text { Preferential } \\
\text { lymphocyte } \\
\text { depletion }\end{array}$ & $\begin{array}{l}\text { Approved for } \\
\text { hairy cell } \\
\text { leukaemia and } \\
\text { lymphoma }\end{array}$ & $\begin{array}{l}\text { Short-course } \\
\text { regimen }\end{array}$ & III \\
\hline Fingolimod & $\begin{array}{l}\text { Lymphocyte } \\
\text { trafficking }\end{array}$ & $\begin{array}{l}\text { Failed phase III } \\
\text { trials for the } \\
\text { prevention of } \\
\text { renal allograft } \\
\text { rejection }\end{array}$ & Daily & III \\
\hline Laquinimod & $\begin{array}{l}\text { Prevention of } \\
\text { T-cell activation }\end{array}$ & $\begin{array}{l}\text { Derived from } \\
\text { roquinimex, } \\
\text { originally } \\
\text { developed } \\
\text { for oncology }\end{array}$ & Daily & III \\
\hline Teriflunomide & $\begin{array}{l}\text { Lymphocyte } \\
\text { antiproliferation }\end{array}$ & $\begin{array}{l}\text { Active metabolite } \\
\text { of rheumatoid } \\
\text { arthritis drug } \\
\text { leflunomide }\end{array}$ & Daily & III \\
\hline
\end{tabular}

well as the long-term effects of cladribine tablets, the effect on immunological parameters and gene expression profiles, quality of life and socioeconomic measures. According to $\mathrm{Dr}$ Vermersch, efficacy data on the CLARITY trial are expected in 2009.

Even though BG12 was originally approved for the treatment of psoriasis vulgaris, its mechanism of action provides a rationale for its use in MS. Animal models of brain inflammation have shown that BG12 improves clinical scores and decreases inflammation by stabilising axons and myelin. ${ }^{96,97}$ Furthermore, BG12 has demonstrated ability in activating the Nrf2 pathway in cellular defence against toxic, metabolic and inflammatory stresses. ${ }^{98}$ In a phase $\|$ clinical study treating RRMS patients with BG12, patients experienced significant reductions in new $\mathrm{Gd}+$ lesions, $\mathrm{T} 2$ lesions and $\mathrm{T} 1$ black holes. ${ }^{99}$ Currently, there are two ongoing phase III BG12 clinical studies: Determination of the Efficacy and Safety of Oral Fumarate in Relapsing-Remitting MS (DEFINE) and Comparator and an Ora Fumarate In Relapsing-remitting Multiple Sclerosis (CONFIRM). It is hoped that these studies will help further define the efficacy and safety of oral BG12 in patients with relapsing MS. symposium proceedings, Dr Kieseier showed that disability - not just physical disability but cognition as well - impairs quality of life in the patient; a higher EDSS score can be argued to present with a lower quality of life. ${ }^{63}$ Many studies have shown that traditional disease-modifying treatment can have a positive effect on more than just disability and relapse rate, and can indeed improve patient quality of life compared with the baseline quality of life assessment over time as well. ${ }^{57,63-67}$

Drug Deliverance - Bringing New Developments to the Table Given the various presentations on new drugs for treating MS at the ENS, many new therapies are anticipated for the future, some of which may be available as early as next year. Among these new developments is the recombinant T-cell receptor ligand RTL1000, which, according to the phase I safety study update, has so far completed two of five planned cohorts assessing safety in escalating intravenous doses, and enrolment for this study is continuing. ${ }^{68}$ The first human-dose study of PI-2301, a second-generation peptide copolymer with a mechanism of action similar to that of glatiramer acetate, found the investigational drug to be generally well tolerated among the 56 healthy male volunteers enrolled; further data collection and analyses are under way and are expected to be available by the end of $2008 .{ }^{69}$ 
A retrospective double-blind analysis of the MRI data collected from the first year of the two-year phase II clinical trial of MN-166 (ibudilast, MediciNova Inc.) in relapsing MS patients has suggested the drug's ability to protect neurons from persistent damage following the formation of acute lesions, preventing conversion to persistent black holes; the presenters noted that further studies regarding black hole formation and disease progression in patients with relapsing or progressive MS are warranted. ${ }^{70}$ The CD52-specific monoclonal antibody alemtuzumab (Bayer/Genzyme), which targets lymphocytes, has been compared with high-dose interferon beta-1a (Rebif) in the phase II CAMMS223 study treating patients with RRMS. The study showed that at the three-year follow-up the antibody was more effective at suppressing relapses and disability in patients than the interferon, with patients in the former group experiencing a $73 \%$ reduction in risk of relapse $(p<0.0001)$ and a $70 \%$ reduction in risk of sustained accumulation of disability $(p<0.0001) . .^{71}$ Subgroup analyses found the treatment effects of alemtuzumab to be consistent across sex, age, race and country, indicating that these findings were independent of patient baseline demographics.

Some of these drugs being developed and studied are oral compounds a class of MS therapies that is amassing increasing interest from researchers and physicians alike. One example of these new oral drugs is laquinimod (Teva Pharmaceutical); MRI data from an extension of the double-blind, randomised, placebo-controlled phase Ilb study have shown that patients benefited in terms of reductions in the mean number of $\mathrm{T} 1$ lesions when switching to laquinimod from placebo, although no significant difference in annualised relapse rate could be discerned. ${ }^{72}$

\section{Summary}

The revelations in MS at the 18th meeting of the ENS have shown a great deal of evidence arguing in support of early treatment, endeavouring to protect patients against disease progression and further deterioration of the CNS. Recent research suggests an increase in the prevalence of the disease, which makes it all the more important to establish an optimal therapy. Many recommendations and even more options exist as to selecting a drug for a patient, and many factors must be considered before choosing to start a patient on any given treatment. Experts in the field have placed heavy emphasis on the benefits of early treatment, when patients can experience greater drug efficacy than at any other phase of the disease course. Many recent drug trials have demonstrated a move towards greater safety and tolerability, while maintaining a high level of efficacy. Therapies are only as effective as the adherence, and programmes providing personal assistance and monitoring have proved successful in upholding a high level of adherence among patients. Many new drugs are in development as well; of these, there is great anticipation for the oral therapies being tested, where it is hoped that the advantage of convenience over the current parenteral options will also help to maintain good adherence levels.
1. Ares B, Prieto JM, Lema M, et al., Prevalence of multiple sclerosis in Santiago de Compostela (Galicia, Spain), Mult Scler, 2007:13(2):262-4.

2. Debouverie M, Louis S, Pittion-Vouyovitch S, et al., Multiple sclerosis with a progressive course from onset in LorraineEastern France, J Neurol, 2007:254(10):1370-75.

3. Papathanasopoulos $P$, Gourzoulidou E, Messinis L, et al. Prevalence and incidence of multiple sclerosis in western Greece: a 23-year survey, Neuroepidemiology, 2008:30(3):167-73.

4. Fasbender P, Kölmel HW, Incidence of Multiple Sclerosis in the Urban Area of Erfurt, Thuringia, Germany, Neuroepidemiology, 2008:30:147-51.

5. Granieri E, Monaldini C, De Gennaro R, et al., Multiple sclerosis in the Republic of San Marino: a prevalence and incidence study, Mult Scler, 2008;14(3):325-9.

6. Iuliano G, Napoletano R, Prevalence and incidence of multiple sclerosis in Salerno (southern Italy) and its province, Eur J Neurol, 2008;15(1):73-6

7. Bach JF, The Effect of Infections on Susceptibility to Autoimmune and Allergic Diseases, N Engl J Med, 2002;347(12):911-20.

8. International Multiple Sclerosis Genetics Consortium; Hafler DA, Compston A, Sawcer S, et al., Risk alleles for multiple sclerosis identified by a genomewide study, N Engl J Med, 2007;357(9):851-62.

9. Ebers $\mathrm{GC}$, Environmental factors and multiple sclerosis, Lancet Neurol, 2008;7(3):268-77.

10. Munger $\mathrm{KL}$, Zhang $\mathrm{SM}, \mathrm{O}^{\prime}$ Reilly $\mathrm{E}$, et al., Vitamin $\mathrm{D}$ intake and incidence of multiple sclerosis, Neurology, 2004;62(1):60-65.

11. Serafini B, Rosicarelli B, Franciotta D, Dysregulated EpsteinBarr virus infection in the multiple sclerosis brain, J Exp Med, 2007;204(12):2899-2912

12. Maggiore C, Trillo-Pazos G, Reynolds R, et al., Detection of EBV antigens in germinal centres in the brain of people with multiple sclerosis, J Neurol, 2008;255(Suppl. 2):056.

13. Sotelo J, Martínez-Palomo A, Ordoñez G, Pineda B, Varicellazoster virus in cerebrospinal fluid at relapses of multiple sclerosis, Ann Neurol, 2008;63(3):303-11.

14. Kuhlmann $T$, Lingfeld $G$, Bitsch $A$, et al., Acute axonal damage in multiple sclerosis is most extensive in early disease stages and decreases over time, Brain, 2002;125:2202-12.

15. Geurts JJ, Wolswijk G, Bö L, et al., Altered expression pattern of group I and II metabotropic glutamate receptors in multiple sclerosis, Brain, 2003;126(Pt 8):1755-66.

16. Craner MJ, Newcombe J, Black JA, et al., Molecular changes in neurons in multiple sclerosis: altered axonal expression of Nav1.2 and Nav1.6 sodium channels and $\mathrm{Na}+/ \mathrm{Ca} 2+$ exchanger, Proc Natl Acad Sci U S A, 2004;101:8168-73.

17. Kornek B, Storch MK, Bauer J, et al., Distribution of a calcium channel subunit in dystrophic axons in multiple sclerosis and experimental autoimmune encephalomyelitis, Brain, 2001;124(Pt 6):1114-24.

18. Kezele IB, Chen JT, Arnold DL, Collins DL, The relation of foca white matter signal abnormality and focal volume loss in multiple sclerosis, Mult Scler, 2007;13(6):809-13.

19. Minneboo A, Uitdehaag BM, Ader $\mathrm{HJ}$, et al., Patterns of enhancing lesion evolution in multiple sclerosis are uniform within patients, Neurology, 2005;65(1):56-61.

20. Agosta F, Rovaris M, Pagani E, et al., Magnetization transfer MR metrics predict the accumulation of disability 8 years later in patients with multiple sclerosis, Brain, 2006;129(Pt 10):2620-27.

21. Coles AJ, Wing MG, Molyneux P, et al., Monoclonal antibody treatment exposes three mechanisms underlying the clinical course of multiple sclerosis, Ann Neurol, 1999:46(3):296-304.

22. Coles AJ, Cox A, Le Page E, et al., The window of therapeutic opportunity in multiple sclerosis: evidence from monoclonal antibody therapy, J Neurol, 2006:253(1):98-108.

23. Beck RW, Chandler DL, Cole SR, et al., Interferon beta-1a for early multiple sclerosis: CHAMPS trial subgroup analyses, Ann Neurol, 2002:51(4):481-90.

24. Anderson VM, Fernando KT, Davies GR, et al., Cerebral atrophy measurement in clinically isolated syndromes and relapsing remitting multiple sclerosis: a comparison of registration-based methods, J Neuroimaging, 2007;17(1):61-8.

25. Audoin B, Ibarrola D, Malikova I, et al., Onset and underpinnings of white matter atrophy at the very early stage of multiple sclerosis-a two-year longitudinal MRI/MRSI study of corpus callosum, Mult Scler, 2007:13(1):41-51.

26. Comi G, Filippi M, Barkhof F, et al.; Early Treatment of Multiple Sclerosis Study Group, Effect of early interferon reatment on conversion to definite multiple sclerosis: a randomised study, Lancet, 2001;357(9268):1576-82.

27. Jacobs LD, Beck RW, Simon JH, et al., Intramuscular interferon beta-1a therapy initiated during a first demyelinating event in multiple sclerosis. CHAMPS Study Group, N Engl I Med, 2000;343(13):898-904.

28. Kappos L, Polman CH, Freedman MS, et al., Treatment with interferon beta- $1 \mathrm{~b}$ delays conversion to clinically definite and McDonald MS in patients with clinically isolated syndromes,
Neurology, 2006:67(7):1242-9.

29. Kappos L, Freedman MS, Polman CH, et al.; BENEFIT Study Group. Effect of early versus delayed interferon beta- $1 \mathrm{~b}$ treatment on disability after a first clinical event suggestive of multiple sclerosis: a 3-year follow-up analysis of the BENEFIT study, Lancet, 2007:370(9585):389-97.

30. Kinkel RP, Kollman C, O'Connor P, et al,; CHAMPIONS Study Group. IM interferon beta-1a delays definite multiple sclerosis 5 years after a first demyelinating event, Neurology, 2006;66(5):678-84.

31. Comi G, Filippi M; PreClSe Study Group, Treatment with glatiramer acetate delays conversion to clinically definite multiple sclerosis in patients with clinically isolated syndrome suggestive of MS, J Neurol, 2008:255(Suppl. 2):059.

32. Patti F, Amato MP, Tola MR, Cognitive and clinical effects of subcutaneous interferon beta- $1 \mathrm{a}$ in patients with early relapsing-remitting multiple sclerosis: 2 - and 3-year results from the COGIMUS (COGnition Impairment in Multiple Sclerosis) study, J Neurol, 2008;255(Suppl. 2):P575.

33. Clerico $M$, Faggiano $F$, Tintoré $M$, et al., Prevention of conversion of clinically isolated syndromes to clinically defined multiple sclerosis. Evidence from a Cochrane meta-analysis, J Neurol, 2008;255(Suppl. 2):0160

34. Comi G, Early treatment, Neurol Sci, 2006;27(Suppl. 1):S8-12.

35. Sellebjerg F, Barnes D, Filippini G, et al.; EFNS Task Force on Treatment of Multiple Sclerosis Relapses, EFNS guideline on treatment of multiple sclerosis relapses: report of an EFNS task force on treatment of multiple sclerosis relapses, Eur J Neurol 2005; 12(12):939-46.

36. O'Connor P, Arnason B, Comi G, et al., Interferon beta-1b $500 \mathrm{mcg}$, interferon beta- $1 \mathrm{~b} 250 \mathrm{mcg}$ and glatiramer acetate: primary outcomes of the Betaferon ${ }^{\circledR} /$ Betaseron ${ }^{\circledR}$ Efficacy Yielding Outcomes of a New Dose study. Program and abstracts of the American Academy of Neurology 60th Annual Meeting, Chicago, Illinois, 12-19 April 2008

37. Mikol DD, Barkhof F, Chang PK, et al. The REGARD trial: a randomized assessor-blinded trial comparing interferon beta $1 \mathrm{a}$ and glatiramer acetate in relapsing-remitting multiple sclerosis, Mult Scler, 2007;13(Suppl. 2):S269, abstract 119

38. Wolansky L, Cook S, Skurnick J, et al., Betaseron [IFNB-1b] vs. Copaxone [glatiramer acetate] in MS with triple-dose gadolinium and 3 T MRI endpoints (BECOME): announcement of final primary study outcomes, Mult Scler, 2007;12(Suppl. 2):S58, poster 206

39. Polman $\mathrm{CH}, \mathrm{O}^{\prime}$ Connor PW, Havrdova $\mathrm{E}$, et al., A randomized, 
placebo-controlled trial of natalizumab for relapsing forms of multiple sclerosis, N Engl J Med, 2006;354(9):899-910.

40. European Medicines Agency (EMEA), Tysabri: Annex I Summary of Product Characteristics, 2006. Available at: www.emea.europa.eu/humandocs/PDFs/EPAR/tysabri/H-603PI-en.pdf (last accessed 2008-07-08).

41. Vollmer T, Panitch H, Bar-Or A, et al., Glatiramer acetate after induction therapy with mitoxantrone in relapsing multiple sclerosis, Mult Scler, 2008;00:1-8.

42. Ramtahal J, Jacob A, Das K, et al., Sequential maintenance treatment with glatiramer acetate after mitoxantrone is safe and can limit exposure to immunosuppression in very active, relapsing remitting multiple sclerosis, J Neurol, 2006;253:1160-64.

43. Le Page E, Comi G, Filippi M; French-Italian MitoxantroneInterferon-beta Trial Group, Comparison of two therapeutic strategies in aggressive relapsing-remitting Ms: Mitoxantrone as induction for 6 months followed by interferon-b- $1 \mathrm{~b}$ versus interferon-b-1b. A 3-year randomized trial, Presented at the 60th AAN Annual Meeting, Chicago, 16 April 2008

44. Khan $\mathrm{O}$, Perumal J, Hreha S, et al., Intense immunsuppression as the initial disease-modifying therapy in clinically active relapsing MS, J Neurol, 2008;255(Suppl. 2):P453.

45. Cordioli C, De Rossi N, Rasia S, et al., Analysis of prevalence, risk factors and prognosis of acute myeloid leukaemia secondary to mitoxantrone therapy in multiple sclerosis patients, J Neurol, 2008;255(Suppl.2):0190.

46. Cohen BA, Khan 0 , Jeffery DR, et al., Identifying and treating patients with suboptimal responses, Neurology, 2004;63: S33-S40.

47. Calabrese M, Filippi M, Rovaris $M$, et al., Evidence for relative cortical sparing in benign multiple sclerosis: a longitudinal MR study, I Neurol, 2008;255(Suppl. 2):0187.

48. Benedetti B, Rovaris M, Pulizzi D, et al., Neuroaxonal brain viability does not differ between benign and early relapsingremitting multiple sclerosis patients, J Neurol, 2008;255 (Suppl. 2):P441

49. Pulizzi A, Rovaris M, Fisniku L, et al., Clinical and conventiona MRI features of non-disabling MS. A large-scale, multicentre, multinational cross-sectional study, J Neurol, 2008;255 (Suppl. 2):0186

50. Mesaros S, Rovaris M, Pagani E, et al., Cognitive dysfunction in benign multiple sclerosis is associated with increased severity of corpus callosum damage, J Neurol, 2008;255(Suppl. 2): 0156

51. Durelli L, Verdun E, Barbero $P$, et al.; Independent Comparison of Interferon (INCOMIN) Trial Study Group, Every-other-day interferon beta-1 $\mathrm{b}$ versus once-weekly interferon beta-1a for multiple sclerosis: results of a 2-year prospective randomised multicentre study (INCOMIN), Lancet, 2002;359(9316): $1453-60$.

52. Schwid SR, Thorpe J, Sharief M, et al.; EVIDENCE (Evidence of Interferon Dose-Response: European North American Comparative Efficacy) Study Group, University of British Columbia MS/MRI Research Group, Enhanced benefit of increasing interferon beta-1a dose and frequency in relapsing multiple sclerosis: the EVIDENCE Study, Arch Neurol, 2005;62(5):785-92.

53. Filippi M, Arnason BGW, Comi G, et al., Magnetic resonance imaging findings of a phase III trial comparing Betaferon with Copaxone treatments in relapsing-remitting multiple sclerosis, J Neurol, 2008;255(Suppl. 2):058.

54 Kappos L, Arnason BGW, Comi G, et al., High proportion of patients free from disease activity in all 3 arms of the highdose Betaferon trial, J Neurol, 2008:255(Suppl. 2):0158.

55. Confavreux C, Galetta SL, Giovannoni G, et al., Complete clinical and magnetic resonance imaging response with natalizumab in multiple sclerosis, J Neurol, 2008;255(Suppl. 2):0159.

56. Tanasescu R, Ticmeanu M, Moraru E, et al., Therapy-related headache in multiple sclerosis patients under interferon-beta: a prospective study, J Neurol, 2008;255(Suppl. 2):061.

57. Hartung H-P, Edan G, Freedman M, et al., The BENEFIT studies: adherence, tolerability and quality of life with Betaferon treatment after a first event suggestive of multiple sclerosis, J Neurol, 2008:255(Suppl. 2):P723.

58. Comi G, Arnason BG, Cook S, et al., Tolerability and adherence to Betaferon and Copaxone in a phase III clinical trial, J Neurol, 2008:255 (Suppl.2):P447.

59. Giovannoni G, Barbarash O, Casset-Semanaz F, et al., Immunogenicity of Rebif New Formulation (interferon beta- $1^{\circ}$ ) in patients with relapsing multiple sclerosis: results from a phase Illb study, I Neurol, 2008;255(Suppl. 2):P325.

60. Giovannoni G, Barbarash O, Casset-Semanaz F, et al., Safety and tolerability of Rebif New Formulation (interferon beta-1a) in patients with relapsing multiple sclerosis: results from a phase IIIb study, J Neurol, 2008;255(Suppl. 2):P720.

61. Al-Sabbagh A, Bennett R, Kozma C, et al., Medication gaps in disease-modifying drug therapy for multiple sclerosis are associated with an increased risk of relapse: findings from a national managed care database, J Neurol, 2008;255 (Suppl. 2):P321.

62. Papuc E, Bartosik-Psujek H, Jamroz-Wisniewska A, et al., Factors determining quality of life of Polish subjects with multiple sclerosis, I Neurol, 2008;255(Suppl. 2):P446.

63. Putzki N, Schicklmaier P, Niemczyk G, et al., Examination of Quality of Life in RRMS Patients during the First Year of Treatment with Interferon beta-1a (IM), Program and abstracts of the American Academy of Neurology 60th Annual Meeting, Chicago, Illinois, 12-19 April 2008.

64. Vermersch P, de Seze J, Delisse B, et al., Quality of life in multiple sclerosis: influence of interferon-beta1 a (Avonex) treatment, Mult Scler, 2002;8(5):377-81.

65. Zivadinov R, Zorzon M, Tommasi MA, et al., A longitudinal study of quality of life and side effects in patients with multiple sclerosis treated with interferon beta-1a, J Neurol Sci, 2003;216(1):113-18.

66. Rudick RA, Miller D, Hass $S$, et al.; AFFIRM and SENTINEL Investigators, Health-related quality of life in multiple sclerosis: effects of natalizumab, Ann Neurol, 2007:62(4):335-46.

67. Simone IL, Ceccarelli A, Tortorella C, et al., Influence of Interferon beta treatment on quality of life in multiple sclerosis patients, Health Qual Life Outcomes, 2006:4:96.

68. Vandenbark A, Burrows G, Ravey E, et al., Phase I safety study update of RTL1000, a recombinant T-cell receptor ligand and specific for an immunodominant MOG peptide, in multiple sclerosis, J Neurol, 2008;255(Suppl. 2):0161.

69. Kovalchin J, Krieger J, Dufour I, et al., Clinical results of the first-in-man single ascending dose study of PI-2301, a second generation peptide copolymer for the treatment of multiple sclerosis, J Neurol, 2008;255(Suppl. 2):P450.

70. Gammans R, Barkhof F, Hulst $H$, et al., MN-166 reduces conversion of new lesions to persistent black holes in multiple sclerosis patients, J Neurol, 2008:255(Suppl. 2):0191.

71. Coles A, on behalf of the CAMMS223 International Study Group, Consistent efficacy with early use of alemtuzumab in relapsing-remitting multiple sclerosis across major demographic subgroups, J Neurol, 2008;255(Suppl. 2):0192.

72. Comi G, Abramsky O, Arbizu T, et al., The effect of laquinimod on MRI-monitored disease activity in patients with relapsingremitting multiple sclerosis: a double-blind active extensión of the multicentre, randomised, double-blind, parallel-group placebo-controlled study, J Neurol, 2008;255(Suppl. 2):0193.

73. Weinshenker BG, Bass B, Rice GP, et al., The natural history of multiple sclerosis: a geographically based study. 2. Predictive value of the early clinical course, Brain, 1989;112(Pt 6): 1419-28.

74. Langer-Gould A, Popat RA, Huang SM, et al., Clinical and demographic predictors of long-term disability in patients with relapsing-remitting multiple sclerosis: a systematic review, Arch Neurol, 2006;63(12):1686-91.

75. Tintoré M, Rovira A, Río J, et al., Baseline MRI predicts future attacks and disability in clinically isolated syndromes, Neurology, 2006;67(6):968-72.

76. Devonshire V, Sayao AL, McDonnell G, et al., Benign multiple sclerosis: an assessment of disability and disease progression in patients with this diagnosis, Mult Scler, 2003;9:S1-S153, P135.

77. Sayao AL, Devonshire V, Tremlett H, Longitudinal follow-up of "benign" multiple sclerosis at 20 years, Neurology, 2007;68: 496-500

78. Amato MP, Zipoli V, Goretti B, et al., Benign multiple sclerosis: cognitive, psychological and social aspects in a clinical cohort, J Neurol, 2006:253(8):1054-9.

79. Costelloe L, Thompson A, Walsh C, et al., Long term clinica relevance of criteria for designating Multiple Sclerosis as benign after ten years of disease, I Neurol Neurosurg Psychiatry, 2008 May 13 (Epub ahead of print).

80. Rudick RA, Fisher E, Lee JC, et al., Use of the brain parenchymal fraction to measure whole brain atrophy in relapsing-remitting MS. Multiple Sclerosis Collaborative Research Group, Neurology, 1999;53(8):1698-1704.
81. Fischer JS, Priore RL, Jacobs LD, et al., Neuropsychological effects of interferon beta-1a in relapsing multiple sclerosis. Multiple Sclerosis Collaborative Research Group, Ann Neurol, 2000;48(6):885-92.

82. Galetta S, Calabresi P, Confavreux C, et al., Natalizumab Increases the Proportion of Patients Free of Clinical or MR Disease Activity in Relapsing Multiple Sclerosis, Program and abstracts of the American Academy of Neurology 60th Annual Meeting, Chicago, Illinois, 12-19 April 2008

83. Yousry TA, Major EO, Ryschkewitsch C, et al., Evaluation of patients treated with natalizumab for progressive multifocal leukoencephalopathy, N Engl J Med, 2006;354(9):924-33.

84. Sorensen PS, Update on Novel Treatments in MS: Natalizumab, Athens, Greece, 23-26 October 2008. Available at: comtecmed.com/CONY/2008/Uploads/assets/speakers\%20abst racts/sorensen.pdf

85. Biogen Idec and Elan Celebrate Second Anniversary of Tysabri ${ }^{\circledR}$ for the Treatment of Multiple Sclerosis. Available at: www.biogenidec.com/site/news-and-media.html?pr_id=../ news/BiogenIDECPR_2008_26.htm (accessed 2008-11-28).

86. Panitch H, Goodin D, Francis G, et al.; EVIDENCE (EVidence of Interferon Dose-response: European North American Comparative Efficacy) Study Group and the University of British Columbia MS/MRI Research Group, Benefits of high-dose, highfrequency interferon beta-1a in relapsing-remitting multiple sclerosis are sustained to 16 months: final comparative results of the EVIDENCE trial, J Neurol Sci, 2005;239(1):67-74.

87. Baum K, O'Leary C, Coret Ferrer F, et al.; BRIGHT Study Group. Comparison of injection site pain and injection site reactions in relapsing-remitting multiple sclerosis patients treated with interferon beta-1a or 1b, Mult Scler, 2007:13(9):1153-60.

88. Halper J, et al., Expanding nursing support to patients with MS: The BETA Nurse Program. CMSC 17th Annual Meeting, San Diego, 28 May - 1 June 2003.

89. Beutler E, Sipe JC, Romine JS, et al., The treatment of chronic progressive multiple sclerosis with cladribine, Proc Natl Acad Sc U S A, 1996;93(4):1716-20.

90. Rice GP, Filippi M, Comi G, Cladribine and progressive MS: clinical and MRI outcomes of a multicenter controlled trial. Cladribine MRI Study Group, Neurology, 2000;54(5):1145-55.

91. Romine JS, Sipe JC, Koziol JA, et al., A double-blind, placebocontrolled, randomized trial of cladribine in relapsing-remitting multiple sclerosis, Proc Assoc Am Physicians, 1999;111(1):35-44

92. Beutler E, Cladribine (2-chlorodeoxyadenosine), Lancet, 1992:340(8825):952-6.

93. Leist TP, Vermersch $P$, The potential role for cladribine in the treatment of multiple sclerosis: clinical experience and development of an oral tablet formulation, Curr Med Res Opin, 2007;23(11):2667-76

94. Cohen BA, Rieckmann P, Emerging oral therapies for multiple sclerosis, Int I Clin Pract, 2007;61(11):1922-30

95. Giovannoni G, Comi G, Cook S, et al., The CLARITY study (CLAdRIbine tablets Treating multiple sclerosis orallY): design of a phase III trial of oral cladribine in relapsing multiple sclerosis, Mult Scler, 2007;13:S7-S273, P808.

96. Schilling $S$, Goelz $S$, Linker $R$, et al., Fumaric acid esters are effective in chronic experimental autoimmune encephalomyelitis and suppress macrophage infiltration, Clin Exp Immunol, 2006;145(1):101-7.

97. Gold R, Linington C, Lassmann $H$, Understanding pathogenesis and therapy of multiple sclerosis via animal models: 70 years of merits and culprits in experimental autoimmune encephalomyelitis research, Brain, 2006;129(Pt 8):1953-71.

98. Lukashev M, Zeng W, Goelz D, et al., Activation of Nrf2 and modulation of disease progression in EAE models by BG00012 (dimethyl fumarate) suggests a novel mechanism of action combining anti-inflammatory and neuroprotective modalities, Mult Scler, 2007;13:S7-S273, P503.

99. Kappos L, Miller D, MacManus D, et al., The efficacy of BG00012 in patients with relapsing-remitting multiple sclerosis: subgroup analyses from the phase llb study, Presented at the 60th AAN Annual Meeting, Chicago, 16 April 2008.

100.Comi G, Filippi M, Treatment with glatiramer acetate delays conversion to clinically definite multiple sclerosis (CDMS) in patients with clinically isolated syndromes (CIS), Program and Abstracts of the American Academy of Neurology 60th Annual Meeting, 12-19 April 2008, Chicago, Illinois, LBS.003. 